\title{
O Teste de Habilidade Específica enquanto cerceador do acesso à licenciatura em Artes Visuais: Um estudo de caso na UFRR
}

\author{
Specific Skill Test as an obstacle for accessing the teaching degree in Visual \\ Arts: a case study at UFRR
}

\begin{abstract}
Resumo
O presente artigo tem como objetivo contribuir com reflexões sobre as ações de acesso nos cursos de graduação de uma maneira geral, e nos cursos de formação de professores de Artes Visuais, de forma específica, realizando um estudo de caso (MAZZOTI, 2006) sobre a experiência de seleção de novos acadêmicos na Universidade Federal de Roraima (UFRR). Na referida universidade, o Teste de Habilidade Específica, em vias de extinção, é a segunda etapa de seleção para entrada de novos estudantes, em que avalia-se os conhecimentos básicos do campo das Artes Visuais. No texto, defenderemos que tal teste não só criou barreiras de acesso via Sistema de Seleção Unificada (SISU), como também reforçou os discursos ideológicos do "talento" e do "dom" (MÉSZÀROS, 2006).
\end{abstract}

Palavras-chave: Artes Visuais, Formação de Professores, Teste de Habilidade Específica.

\begin{abstract}
This article aims to contribute to reflections on the access actions in undergraduate courses in general, and Visual Arts teaching degrees particularly, by conducting a case study (MAZZOTI, 2006) about new academics' selection experience at Federal University of Roraima (UFRR). In that university, Specific Skill Test, on the verge of extinction, is the second stage of selection for admission of new students, in which basic knowledge in the field of Visual Arts is evaluated. In the text, we will hold that such test has not only created barriers to access via Unified Selection System (SISU), but have also strengthened the ideological discourses of "talent" and "gift" (Meszaros, 2006).
\end{abstract}

Keywords: Visual Arts, Teacher Training, Specific Skill Test.

\section{Introdução}

Criado em 2010, o curso de Licenciatura em Artes Visuais da Universidade Federal de Roraima teve até 2012 duas etapas de ingresso. Uma geral, que todos os pleiteantes a vagas realizam, e uma segunda, chamada de Teste de Habilidade Específica (THE). O THE será utilizado nesse texto como dispositivo para problematizarmos concepções vinculadas a exigirem determinadas habilidades específicas dos estudantes para curso de formação de professores em geral e nas Artes Visuais em particular. Existem habilidades 
a priori? Pode o avaliador se considerar um precogs ${ }^{1}$ ? Alguém dotado de "poderes" capaz de mediante um teste, uma avaliação, poder determinar a capacidade do candidato(a) em formar-se um professor? De alguma maneira essa prática relaciona-se com o discurso ideológico do "dom"?

Para responder a essas perguntas que nos inquietam, optamos por realizar uma investigação de estudo de caso para debatermos as questões vinculadas as mesmas. Nesse sentido, o estudo de caso foi entendido a partir das reflexões de Mazzotti (2006):

Os critérios para identificação e seleção do caso, porém, bem como as formas de generalização propostas, variam segundo a vinculação paradigmática do pesquisador, a qual é de sua livre escolha e deve ser respeitada. O importante é que haja critérios explícitos para a seleção do caso e que este seja realmente um 'caso', isto é, uma situação complexa e/ou intrigante, cuja relevância justifique o esforço de compreensão. (MAZZOTTI, 2006, p. 650)

Para tanto a base da análise foi documental, utilizando os THE dos anos de 2011, 2012, 2013, requeridos junto ao Departamento de Registro e Controle Acadêmico (DERCA). O THE de 2010 não foi fornecido pelo DERCA, mas pela constância das características das questões dos anos citados, entendemos que esse fato não prejudicou a avaliação do THE de uma maneira geral, com a mostra dos últimos três anos.

\section{Sobre o curso e o ingresso no mesmo}

O curso é realizado na Universidade Federal de Roraima (UFRR), instituição federal localizada no estado mais setentrional do Brasil, na sua capital Boa Vista. A capital possui cerca de $65 \%$ da população do estado, criado em 1988, que tem cerca de 470 mil pessoas, é o menos populoso do país. A licenciatura em Artes Visuais foi parte do Programa de Apoio a Planos de Reestruturação e Expansão das Universidades Federais (REUNI) que visa criar condições para ampliação do acesso e permanência nas instituições superiores, instituído pelo Decreto no 6.096, de 24 de abril de 2007, dentro das ações do Plano de Desenvolvimento da Educação.

A escolha pela criação de uma licenciatura nessa área de conhecimento se deu em razão de não haver em todo estado mais de 10 professores licenciados em Artes Visuais, sendo a disciplina utilizada como complementação da carga horária para docentes de outras

\footnotetext{
${ }^{1}$ Nome dado no filme "Minority Report - a nova lei (2002)" a seres com a capacidade de prever o futuro.
} 
áreas. Em razão dessa especificidade do estado, a necessidade de formação de docentes nesse campo do conhecimento foi imperativa para a construção desse curso.

Durante a escritura dessas linhas, no primeiro semestre de 2013, o curso possui três turmas que fizeram seleção nos anos de 2010, 2011 e 2012. A seleção era constituída por duas etapas. Uma geral, com prova do vestibular para todos os inscritos e uma segunda etapa, prevista do Projeto Político Pedagógico (PPP), do THE.

além das provas universais, a entrada de candidatos para o curso de Graduação em Artes Visuais - Licenciatura realizar-se-á com a efetivação do Teste de Habilidade Específica, prova de segunda fase, em conhecimentos básicos e de princípios de plástica e estética.(UFRR, 2011, p. 42)

No PPP, optou-se por inserir "conhecimentos básicos e de princípios de plástica e estética" apenas na segunda fase e não nas provas universais, como se apenas os futuros acadêmicos da licenciatura deveriam ter esses conhecimentos. O vestibular e demais provas seletivas para o ingresso nas Instituições Federais de Ensino Superior (IFES) orientam em grande medida as valorações de áreas de conhecimento nas escolas de educação básica. Assim como as características das questões nas provas também em grande parte nortearão as práticas pedagógicas. A inserção de questões interdisciplinares, que proponham reflexões sobre as Artes Visuais, para todos os estudantes, poderia ser um caminho que fortalecesse esse campo de conhecimento na educação básica como um todo. Claro que questões mais interdisciplinares exigirão uma formação diferente dos estudantes, do que, por exemplo, questões que exijam apenas a reprodução de informações, o "decoreba". Se por um lado a inserção de questões do campo das Artes Visuais poderá resultar em uma maior atenção à esse campo do conhecimento daqueles que estão em vias de tentar o ingresso nas IFES, pode por outro lado orientar para uma prática educativa reprodutora de informações, na medida que o professor "em lugar de comunicar-se, o educador faz 'comunicados' e depósitos[...] Eis ai a concepção 'bancária' da educação" Freire (1987, p.58).

A referência ao THE no PPP aprofunda sobre quais conhecimentos ele irá avaliar:

Quanto ao teste de habilidades específicas, entende-se que o candidato detenha prática e teoria básicas que lhe foram proporcionadas no ensino básico enquanto emprego e uso desses saberes aliados à sua criação. Considerar-se-á não somente a destreza mecânica, mas todo o conhecimento básico necessário que se encontra nas teorias sobre plástica e desenho, tais como fundamentos sobre luz e a sombra e a perspectiva enquanto percepção de profundidade. Nesse teste, considera-se relevante o 
aspecto da significação para as Artes Visuais, no sentido do domínio de sua sintaxe e não apenas o da destreza e facilidade para a expressão plástica. Assim, acredita-se que será garantida a qualidade no ensino e no aprendizado em artes. (UFRR, 2011, p.42)

Embora, por princípio, questionamos a validade de uma avaliação que, a priori, já determine quem pode vir a ser professor, não podemos deixar de notar uma contradição interna na própria estrutura propositiva do referido exame. Se o curso foi criado pela quase inexistência de docentes da área no estado de Roraima, como na seleção irá o candidato deter "prática e teoria básicas que Ihe foram proporcionadas no ensino básico?" A disciplina é utilizada como complementação de carga horária para docentes de outras áreas. Embora a possibilidade da interdisciplinaridade exista e reconhecemos que o conhecimento assim é produzido, há limites na prática de um docente de matemática, que complementa sua carga horária em Artes, assim como haveria limites em um docente de Artes Visuais que complementasse sua carga horária na Matemática. São campos diferentes.

Dessa maneira o THE acaba por jogar toda a responsabilidade no educando, pois se o estado não proporcionou à ele professores formados na especificidade da disciplina, se a sociedade não possibilita espaços de vivências nas Artes Visuais, é o indivíduo que em última instância deverá busca-lo.

Por fim, o THE deverá garantir dessa maneira "a qualidade no ensino e no aprendizado em artes". Essa afirmação já desconsideraria qualquer preocupação do PPP acerca das disciplinas, avaliação, princípios pedagógicos, pois a qualidade desde a perspectiva do ensino e da aprendizagem, já estaria avalizada. Essa afirmação é uma demonstração muito clara da relevância data ao exame, que separa "o joio do trigo", e os aprovados já estariam garantindo a qualidade de sua formação, independente do resto do PPP e da vida concreta na academia, seus professores, orientações pedagógicas, participação em pesquisas e na extensão, etc. Flertando com o discurso ideológico do "Dom" que mais adiante será tratado.

\section{Mas o que continha o THE?}

Para atingir os objetivos propostos no THE o teste tinha sempre cinco questões e entre suas instruções não permitiam desenhos fora do espaço indicado e o uso de compasso, esquadro, transferidores e assemelhados.

No exame realizado, no ano de 2011 , eram as seguintes questões: 
- Objetos foram expostos e o candidato deveria fazer uma composição em A3, enfatizando perspectiva, enquadramento, luz e sombra.

- Criar uma ilustração em A3 a partir do poema "Rosa de Hiroshima" de Vinícius de Moraes.

- Fazer relações sobre Arte e Ecologia, partindo da abertura da novela Passione, que tinha trabalhos do artista Vik Muniz.

- Criar uma sequência de imagens em espaços pré-definidos a partir do poema "O caboclo e o Rio" de Eliakin Rufino. Eram seis espaços de 9x7cm.

- Relacionar movimentos artísticos com imagens. Os "movimentos" eram abstracionismo, expressionismo, impressionismo, modernismo, renascimento. Com imagens de Monet, Michelangelo, Tarsila, Munch e Kandinsky.

Em 2012 as questões eram:

- Realizar uma releitura cubista de um trabalho de Raimundo Cela.

- Fazer uma rosácea em um circulo em tons de preto e branco.

- Desenhar uma interpretação em uma folha A4, da frase "Sinto-me nascido a cada momento. Para a eterna novidade do mundo" de Fernando Pessoa.

- Dissertar sobre a relação entre Arte e Natureza.

- Identificar os movimentos ou artistas de cinco imagens

No teste do ano de 2013 as questões eram as seguintes:

- Compor um desenho a partir de uma imagem utilizando linha, superfície, volume, luz e cor,.

- Criar uma releitura do "Lavrador de Café" de Portinari, em um espaço de $11 \times 10 \mathrm{~cm}$. Essa questão faz referência a abordagem triangular de Ana Mae Barbosa. Diz seu enunciado: "A livre expressão, enfatizando a visão pessoal como interpretação da realidade, a emoção como guia de expressão e a originalidade como ideal; a leitura de obras de arte, como ação estética questionadora que favorece descobertas e desperta a capacidade crítica do aluno; e a contextualização da obra de arte como produção cultural, são as três propostas pela Proposta Triangular do Ensino da Arte".

- Novamente é solicitado a relação entre imagens e agora linguagens, sendo elas: instalação, performance, body-art e land-art. Com trabalhos de Robert Smithson, Gina Pane, Bruce Nauman e Adriana Varejão.

- Escrever um texto tendo como referência o "Abaporu" de Tarsila do Amaral. 
- Nova relação entre imagens e movimentos ou no caso em questão artistas, sem indicar quais movimentos e ou artistas.

O THE procurou problematizar uma linguagem bem específica, o desenho, com lápis preto; a releitura enquanto prática isolada, embora citasse a Abordagem Triangular, desconsiderava a concepção da proposta de Ana Mae Barbosa que, dialogando com as elaborações do DBAE (Basic Design Movement), nos Estados Unidos, o Critical Studies, e com as Escuelas al Aire Libre do México, articula a relação entre o fazer, a contextualização e a leitura. A proposta triangular possibilitou o debate no Brasil, sobre o ensino das Artes Visuais enquanto campo de conhecimento. Ainda sobre essa abordagem, segundo Bredariolli (2010):

A Abordagem Triangular foi estruturada como um organismo, articulado pela interação e interdependência entre as ações totalizadoras - a 'leitura' crítica, contextualização e produção realizadas em diálogo entre professor e o aluno. Há uma condução, mas também a abertura para a mudança de caminho, condicionada à participação do aluno. Por essa condição a Abordagem Triangular assume a característica de um sistema epistemológico e não metodológico de Ensino da Arte. (BREDARIOLLI, 2010, p. 36)

Isolar um elemento significa retirar do ação docente qualquer "interação e interdependência" entre as dimensões.

Outro ponto do teste que é encontrado em todos os anos pesquisados é a prática de questões do tipo "enumere a segunda coluna de acordo com a primeira", ou seja, a nível de informação, a reprodução "'bancária". Se há alguma habilidade específica que se possa encontrar nesse conjunto de questões, é a de superar, individualmente a negação desse campo de conhecimento na educação básica, em um estado praticamente sem professores do campo das Artes Visuais. Seja pelas condições que possibilitem acesso à ela, financeira, por exemplo, seja pelo interesse individual pelas artes de uma maneira geral, e as Artes Visuais em particular.

O teste, quando possibilita algum tipo de produção em alguma linguagem, limita sua avaliação a elementos formais, construídos somente a partir do desenho, feito esse com lápis preto. Em espaços de $9 \times 7 \mathrm{~cm}, 11 \times 10 \mathrm{~cm}$, A4 e A3.

Nessas condições a primeira questão citada na introdução desse texto se impõe, existem habilidades a priori, para permitir a um ser humano de vir a ser um educador (a)? 0 teste avaliaria "conhecimentos básicos e de princípios de plástica e estética", mas esses 
conhecimentos no contexto das Artes Visuais na educação básica são negados dos educandos. E mesmo se não fossem negados, em que medida relacionar uma figura com o artista ou o período/movimento, fará o sujeito que disputa uma vaga ser mais comprometido com essa vaga pública que disputa, com a profissão que irá se formar, com aqueles que estarão em interação com ele no papel social de estudantes. Freire (1996, p.50) entre seus "saberes necessários à prática educativa" tece considerações sobre o inacabamento, o processo de transformação constante de si, e afirma que, "Aqui chegamos ao ponto de que talvez devêssemos ter partido. O do inacabamento do ser humano". É justamente o inacamento de homens que mulheres que permite a eles e elas se educarem, pois, estão em constante busca do conhecimento, do aprender. A possibilidade de poder vir a ser um acadêmico e posteriormente um docente, jamais poderia ser negada a ninguém pela falta que a própria sociedade teve na equidade de oportunidades, o THE desconsidera o que deveria ser o ponto de partida, o nosso inacabamento.

A capacidade de realizar desenhos em espaços diminutos de maneira nenhuma é fundamental para possibilitar a entrada na academia. Nem o desenho é a única linguagem no campo das Artes Visuais, nem a capacidade ou não de produção de conhecimento nessa linguagem é inata e não pode ser desenvolvida em todos(as) durante o curso, pois ela é uma potencialidade humana. A primazia do desenho sobre as outras linguagens é algo que foi reproduzido por muitos desde o Renascimento, Hauser (2000, p.342) já afirmava que foi nesse período que o desenho toma o lugar central no campo das Artes Visuais, nas suas palavras "o desenho tornou-se a fórmula direta da criação artística, porquanto deu a expressão mais impressionante possível ao elemento fragmentário [...] que, em última análise, está presente em toda e qualquer obra de arte". Mesmo com as modificações ocorridas nos últimos séculos é essa linguagem que arbitrariamente foi escolhida para o teste e não a escultura, a pintura, a performance, a instalação, etc. O THE deixa claro que é necessário saber desenhar, com lápis preto, para poder entrar em um curso de licenciatura em Artes Visuais.

\section{A negação da potencialidade humana}

A organização da nossa sociedade é desigual, o próprio processo de humanização é negado, "constatar esta preocupação implica, indiscutivelmente, reconhecer a desumanização, não apenas como viabilidade ontológica, mas como realidade histórica." (FREIRE, 1987, p.30). A estrutura da sociedade capitalista tem por trás de si edifício da reprodução ampliada do capital ${ }^{2}$. Mészàros (2006a) sistematiza essa organização em três

\footnotetext{
${ }^{2}$ Nas palavras de Mészàros (2002, p.102) "produtor potencial de valor historicamente específico".
} 
eixos fundamentais na estrutura do capital, a necessidade de haver uma separação entre produção e controle, produção e consumo, dominação e subordinação. Em razão disso, chegamos à divisão social do trabalho e nosso momento histórico, tendo isolados de si o trabalho intelectual do trabalho braçal, quem manda de quem obedece, quem produz de quem consome.

Essa divisão social do trabalho necessita dos discursos ideológicos ${ }^{3}$ para reproduzir essa situação, e aqui chegamos novamente no THE objeto das reflexões do presente texto. Não há por parte do estado uma estrutura que não só incentive o contato com o campo das Artes Visuais, mas também a produção. Assim como não podemos considerar que há um sistema da arte no estado de Roraima, Cauquelin (2005, p.15) define esse sistema como "o papel dos diversos agentes: o produtor, o comprador - colecionador ou aficionado - passando pelos críticos, publicitários, curadores, conservadores, instituições, os museus". Nas escolas de educação básica atuam menos de 10 professoras licenciadas em Artes Visuais, essa exclusão da ampla parte da população da produção de conhecimento em e sobre Artes Visuais faz dessa parcela da sociedade vítima e não culpada.

O THE, no momento que cobra conhecimentos que a sociedade e o estado negam à maior parte da população, reforça o discurso ideológico do Dom, do talento bíblico, parábola no Evangelho de João ( Capítulo 25, vers. 14-29) que contribuiu para relacionar o talento com um presente recebido. Esses vínculos históricos encontram ressonância naqueles que defendem, mesmo que não saibam, o inatismo:

A epistemologia que sustenta esse modelo pedagógico é também denominada apriorista, palavra derivada da expressão a priori, significativa "daquilo que é posto antes", no caso em tela, a bagagem genética/hereditária. Essa epistemologia acredita que o ser humano nasce com o conhecimento já programado na sua herança genética (NEVES e DAMIANI, 2010, p. 04)

Tal concepção acaba intensificando uma visão que legitima uma imensa desigualdade existente em nossa sociedade, fato que todo educador comprometido com uma educação problematizadora deve evitar pois:

... a arte não é uma das especialidades entre as muitas preservadas para poucos afortunados, e sim uma dimensão essencial da vida humana em geral. Na forma em que a conhecemos, a arte é profundamente afetada pela alienação, porque a 'concentração exclusiva do talento artístico em alguns'

\footnotetext{
${ }^{3}$ Chauí (2011, p.99) afirma, "A ideologia é uma das formas de práxis social: aquela que partindo da experiência imediata dos dados da vida social, constrói abstratamente um sistema de ideias ou representações sobre a realidade."
} 
está inseparavelmente ligada à 'sua supressão nas massas como resultado da divisão do trabalho' (MÉSZÀROS, 2006, p.191).

Esse processo é visto em todas as regiões do país, em seleções de ingresso de diversos cursos de Artes Visuais. A título de exemplo, são encontrados THE's no Instituto Federal do Ceará (Campus Arcati), Universidade Federal do Rio de Janeiro, Universidade de Brasília, Universidade Federal de Minas Gerais, Universidade Federal da Paraíba, Universidade Federal do Rio Grande do Sul, entre outras.

\section{Síndrome precogs}

Como já explicado antes, o termo precogs tomado de empréstimo do filme Minority Report, que conta a história de uma sociedade que possui seres capazes de ver o futuro. Esses seres ficam em um local prevendo assassinatos. Os prováveis assassinos eram presos antes de terem cometido esse crime capital. Transpondo este enredo para as nossas discussões, fazemos a seguinte indagação: Não cumpriu esse papel o THE? Antes de cursarem a licenciatura já se definia quem teria essas tais "habilidades específicas". E, diga-se de passagem, habilidades "limitadas" e pré-determinadas, pois, é importante considerar que no THE da instituição aqui pesquisada atribui ênfase ao desenho.

No filme citado uma questão se sobressai, é legítimo prender uma pessoa somente pela intenção que ela possa ter, sem ela ter de fato cometido o crime? Na obra adaptada, do escritor Philip K. Dick, a agência Pré-Crime é responsável de realizar as prisões. Na UFRR - DERCA acaba tento o papel de impedir a entrada de novos acadêmicos por critérios previamente estabelecidos. O processo de formação de docentes, das mais diversas profissões, é contínuo, sendo o curso de graduação apenas uma "formação inicial" que possibilita a construção de habilidades mínimas para o exercício da profissão. Nos formamos enquanto escrevemos esse texto e no momento que essas linhas são lidas já não somos os mesmos, e, esperamos, que quem leia essas palavras também, de alguma maneira, mude. A compreensão que o processo de formação humana é um "vir a ser" ou "estar sendo" elaborado por Paulo Freire, choca-se com qualquer concepção de formação docente que negue a chance de indivíduos cursarem licenciaturas em geral, e no caso em questão, a de Artes Visuais na UFRR em particular, por ter sido negados à eles a vivência nesse campo do conhecimento durante sua vida.

\section{Possibilidades futuras}

Ao fim e ao cabo o THE busca responsabilizar individualmente um problema social. Sendo ele também uma construção histórica, coletiva, é atuando na história e coletivamente 
que superaremos concepções que não democratizem o acesso à universidade, ao campo das Artes e em particular, às Artes Visuais. O curso está em processo de reformulação do PPP. Esse processo, construído coletivamente, conta com ampla participação de toda a comunidade acadêmica. Já houve duas rodadas de discussões, e em assembleia do curso optou-se por retirar essa exigência que tem o THE, do processo seletivo. Seja pelas razões levantadas aqui, seja por outras tantas citadas, como a insegurança que afasta alguns de fazerem a seleção, e a impossibilidade de candidatos ingressarem via Sistema de Seleção Unificada (SISU), esse sistema possibilita que aqueles que fizeram o Exame Nacional do Ensino Médio (ENEM) possam pesquisar vagas disponíveis em qualquer universidade participante e disputá-las com sua nota.

As reflexões contidas aqui se deram pari passu ao processo de exclusão do THE, elas serviram de subsídios para os debates, nem sempre consensuais. Esperamos que as mesmas contribuam para cada fez mais termos uma universidade, e cursos de licenciatura em Artes Visuais, comprometidos em superar as imensas desigualdades sociais do nosso tempo, não utilizando elas enquanto cerceadoras da possibilidade histórica do ser humano em "ser mais".

\section{Referências}

BREDARIOLLI, R. Choque e formação: sobre a origem de uma proposta para o ensino da arte. In. BARBOSA, A. M.; CUNHA, F. P. Abordagem Triangular no ensino das Artes e Culturas Visuais. São Paulo: Cortez, 2010. p.27 - 42.

CAUQUELIN, A. Arte Contemporânea: uma introdução. São Paulo: Martins Fontes, 2005.

CHAUÍ, M. O que é ideologia. São Paulo: Brasiliense, 2011.

FREIRE, P. Pedagogia do Oprimido. Rio de Janeiro: Paz e Terra, 1987.

Pedagogia da Autonomia: saberes necessários à prática educativa. São

Paulo: Paz e Terra, 1996.

HAUSER, A. História social da arte e da literatura. São Paulo: Martins Fontes, 2000.

MAZZOTTI, A. "Usos e abusos dos estudos de caso". Cadernos de Pesquisa, v. 36, n. 129, 2006. p. 637-65.

MÉSZARÓS, I. A teoria da Alienação em Marx. São Paulo: Boi Tempo, 2006. 
Para além do capital. São Paulo: Boitempo, 2006a.

NEVES, R. A. e DAMIANI, M. F. Vygotsky e as teorias da aprendizagem. In: UNIrevista UNISINOS. São Leopoldo: Vol. 1, n²: 01-10.

UFRR. Projeto Pedagógico do Curso de Licenciatura em Artes Visuais. Boa Vista, 2011.

Vinícius Luge

Universidade Federal de Roraima

Ivete Souza da Silva

Universidade Federal de Roraima

Recebido em: 23/09/2013

Aprovado em: 15/10/2013 